\title{
Programa de Redução da Morbimortalidade por Acidentes de Trânsito: Mobilizando a Sociedade e Promovendo a Saúde
}

\author{
Programme for Reduction Traffic Accident Morbimortality: Mobilizing Society \\ and Promoting Health
}

Projeto Promoção da Saúde

Secretaria de Políticas de Saúde/MS

\begin{abstract}
Os acidentes e as violências representam modernas epidemias que assolam países do mundo inteiro, configurando um conjunto de agravos à saúde, que pode ou não levar a óbito, no qual se incluem as causas ditas acidentais - devidas a trânsito, trabalho, quedas, envenenamentos, afogamentos e outros tipos de acidentes - e a causas intencionais, como agressões e lesões autoprovocadas. ${ }^{3}$
\end{abstract}

Sob essa concepção, o Ministério da Saúde (MS) assume sua participação juntamente com a sociedade civil e outros setores na discussão e resolução do problema, definindo especificidades dessa participação, propondo estratégias de promoção da saúde e de prevenção de acidentes e, também, adequando as ações relativas à assistência, à recuperação e à reabilitação das vítimas de alguma forma de violência.

Nesse sentido, visando instrumentalizar a Política Nacional de Redução de Morbimortalidade por Acidentes e Violência no que diz respeito à morbimortalidade relacionada aos acidentes de trânsito, o Ministério da Saúde apresenta o Programa de Redução da Morbimortalidade por Acidentes de Trânsito: Mobilizando a Sociedade e Promovendo a Saúde, com destaque para as ações de prevenção a ser implementadas nos aglomerados urbanos onde se concentra a maior parte da malha viária e das ocorrências de casos e óbitos.

O programa tem como objetivo implementar ações de promoção da saúde por meio da articulação e mobilização de setores governamentais, nãogovernamentais e da população em geral, visando a redução da morbimortalidade causada pelos acidentes de trânsito.

Os acidentes de trânsito geram, entre as causas externas, elevado percentual de internação, além de altos custos hospitalares, perdas materiais, despesas previdenciárias e grande sofrimento para as vítimas e seus familiares. Dados do Sistema de Informação so- bre Mortalidade (SIM/MS) informam que, em 1998, ocorreram no Brasil 30.994 óbitos por acidentes de transporte, significando $26,3 \%$ entre as causas externas. A mortalidade proporcional por causa foi de 3,3\% e o coeficiente de mortalidade, de 19,16 por 100.000 habitantes. Esses dados expressam a relevância epidemiológica e social do problema e a necessidade de articulação intersetorial entre as áreas de saúde, trânsito e a sociedade.

Diante dessas evidências, vem se consolidando no País uma política de redução da violência, cujo marco inicial legal pode ser remetido, no que se refere especificamente aos acidentes de trânsito, ao Código de Trânsito Brasileiro, que entrou em vigor em 22 de janeiro de 1988 , por meio da Lei $n^{\circ} 9.503$, privilegiando a segurança e a preservação da vida, caracterizando-se então como um conjunto significativo de medidas de prevenção, e não somente como instrumento punitivo.

Expressando um processo de responsabilização, e em resposta à necessidade de uma intervenção mais ampliada sobre a problemática, no âmbito do Ministério da Saúde foram instituídos o Comitê Técnico Científico de Assessoramento ao Grupo Técnico para Acidentes e Violência (Portaria n ${ }^{\circ}$ 3.566/GM de 22/9/ 1998) e o Comitê de Prevenção de Acidentes e Violências na Infância e Adolescência (Portaria nº 3.733/ GM de 14/10/1998) sendo, em 16 de maio de 2001, publicada a Portaria $\mathrm{n}^{\circ} 737$ do Ministério da Saúde, que formalizou a Política Nacional de Redução de Morbimortalidade por Acidentes e Violências.

Nesse contexto emerge este programa, coordenado pelo Ministério da Saúde e executado pelos governos estaduais e municipais, o que viabiliza sua execução com capilaridade. Toma como diretrizes o trabalho intersetorial com participação social, garantindo que a questão seja tratada de forma abrangente e compartilhada, facilitando o alcance de seus objetivos e potencializando seus efeitos. 


\section{Áreas prioritárias para o desenvolvimento do programa}

A distribuição territorial da população brasileira apresenta marcante concentração em aglomerados urbanos situados, em sua maioria, na região Sudeste e no litoral. Existem no País, atualmente, 49 aglomerados urbanos nos quais se concentram $48 \%$ da população. Além disso, segundo dados do Departamento Nacional de Trânsito - Ministério da Justiça Denatram/MJ, a maior parte da malha viária faz a ligação entre esses grandes aglomerados, que são, também, pólos de atividade econômica. A população flutuante que circula por essas estradas, oriunda de diferentes localidades, é também elevada, ainda que dados mais precisos não estejam disponíveis.

A definição das áreas prioritárias de atuação do programa obedeceu a dois critérios: óbito por acidente de trânsito como marcador (SIM/MS-98) e o conceito de aglomerados urbanos (IDB/1998; Ipea/ IBGE/Nesur/Unicamp, 1999). ${ }^{1}$ Foram enumerados todos os aglomerados urbanos brasileiros, metropolitanos e não-metropolitanos, e capitais. Estudaramse a frequiência dos óbitos, o coeficiente de mortalidade específico e a mortalidade proporcional por acidentes de transporte. Por meio da ponderação desses três indicadores, foi construído um índice que leva em conta a magnitude, o risco e a importância dos acidentes de transporte na mortalidade geral e sua distribuição nesses aglomerados.

A Figura mostra o índice construído aplicado às cidades e aos aglomerados urbanos priorizados no programa, que abrangerá 84 municípios em 26 áreas metropolitanas de 14 unidades da Federação, atingindo uma população total de 46.365 .905 habitantes, conforme mostra a Tabela.

Exceção ao critério de aglomerado urbano utilizado foi a inclusão de três capitais de estados da região Norte (Boa Vista, Porto Velho e Macapá), por apresentarem isoladamente risco elevado para óbitos por acidentes de trânsito.

\section{Diretrizes metodológicas}

O programa está pautado nas seguintes diretrizes:

- planejamento participativo, em que os diversos atores sociais, incluindo a própria população, possam construir seus planos locais e regionais, atendendo a suas especificidades e particularidades;

- descentralização administrativa, diretriz constitucional e princípio legal do Sistema Único de Saúde (SUS), que permeia a implementação de todas as políticas de saúde;

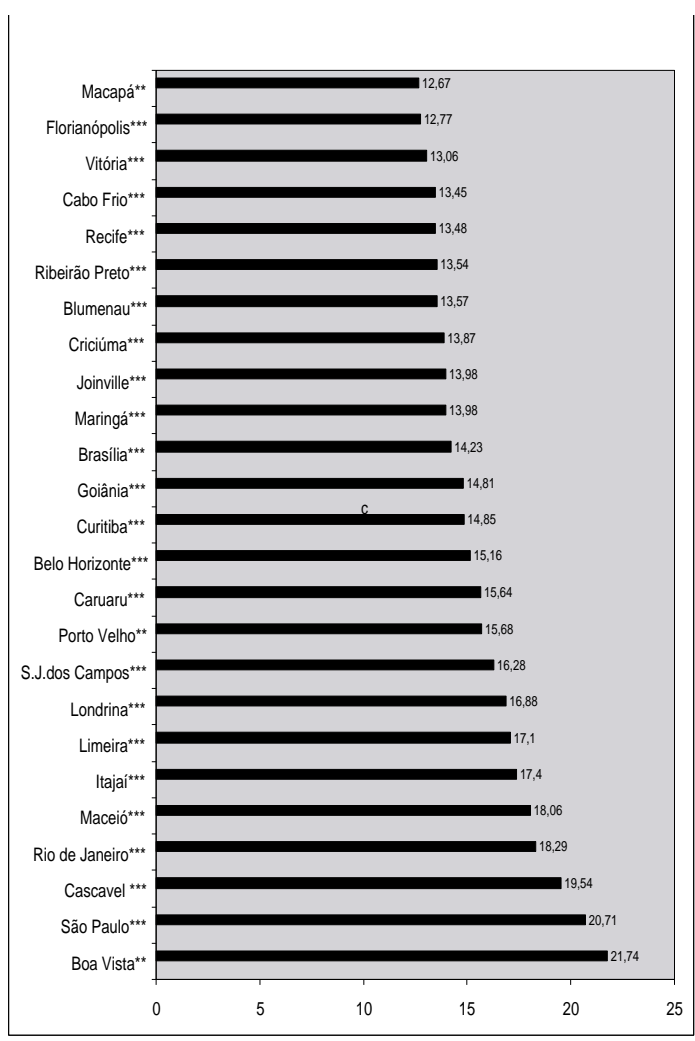

Figura - Índice* para Acidentes de Trânsito. Cidades e Aglomerados Urbanos Priorizados. Brasil, 1998.

*Indice - composto pelos indicadores: freqüência de óbitos, coeficiente de mortalidade proporcional para acidentes de transporte

**Capital exclusiva

***Cidade pólo e respectivo aglomerado

- intersetorialidade, concebida como estratégia de envolvimento de múltiplos atores, organizados em torno de um objetivo comum, o que implica o estabelecimento de parcerias com responsabilidades compartilhadas nas ações de prevenção e de promoção da redução da morbimortalidade por acidentes de trânsito.

Compreendendo que os acidentes de trânsito dizem respeito às relações que se estabelecem entre as condições do veículo, das vias de trânsito e das pessoas, o programa prioriza as ações de mobilização e a capacitação da sociedade e dos sujeitos envolvidos, na perspectiva de que, localmente, ocorra o desenvolvimento de políticas públicas formuladas com a participação da população e sob a responsabilidade dos vários setores da sociedade voltados para promover mudanças positivas na situação atual.

\section{Estratégias operacionais}

- Constituir Comissão Técnica de Acompanhamento do Programa, sob a coordenação da Secretaria de Políticas de Saúde/MS, composta por membros do Ministério da Saúde, que ficará responsável 
Tabela - Áreas metropolitanas priorizadas na primeira etapa.

\begin{tabular}{|c|c|c|c|}
\hline Região & UF & $\begin{array}{l}\text { Área } \\
\text { metropolitana }\end{array}$ & $\begin{array}{r}\text { Total } \\
\text { População } \\
\end{array}$ \\
\hline \multirow[t]{3}{*}{ Norte } & Roraima & Boa Vista & $163.024 *$ \\
\hline & Rondônia & Porto Velho & $304.585^{*}$ \\
\hline & Amapá & Macapá & $244.972 *$ \\
\hline \multirow[t]{3}{*}{ Nordeste } & Alagoas & Maceló & $766.498^{*}$ \\
\hline & Pernambuco & Recife & 2.890 .829 \\
\hline & & Caruaru & $259.725^{*}$ \\
\hline \multirow[t]{8}{*}{ Sudeste } & Rio de Janeiro & Rio de Janeiro & 10.247 .097 \\
\hline & & Cabo Frio & 113.813* \\
\hline & São Paulo & São Paulo & 16.393 .741 \\
\hline & & Limeira & 401.067 \\
\hline & & Ribeirão Preto & $467.908^{*}$ \\
\hline & & S. J. dos Campos & 1.021 .975 \\
\hline & Minas Gerais & Belo Horizonte & 3.529 .886 \\
\hline & Espírito Santo & Vitória & 1.187 .144 \\
\hline \multirow[t]{9}{*}{ Sul } & Paraná & Curitiba & 1.908 .659 \\
\hline & & Londrina & 530.455 \\
\hline & & Cascavel & $231.901 *$ \\
\hline & & Maringá & $280.644^{*}$ \\
\hline & Santa Catarina & Florianópolis & 431.310 \\
\hline & & Joinville & $418.569 *$ \\
\hline & & Blumenau & $240.302 *$ \\
\hline & & Itajaí & $141.976^{*}$ \\
\hline & & Críciúma & 164.973* \\
\hline \multirow[t]{3}{*}{ Centro Oeste } & Goiás & Goiânia & 1.345 .942 \\
\hline & Distrito Federal & Brasília & 2.043 .007 \\
\hline & Mato Grosso & Cuiabá & 655.236 \\
\hline Total geral & 14 & 26 & 46.365 .905 \\
\hline
\end{tabular}

Fonte: IBGE, 1998. *População do município.

pela assessoria, pelo planejamento, pela avaliação e supervisão das ações levadas a efeito pelos estados e municípios.

- Sensibilizar os gestores municipais para que incorporem os conteúdos desse programa às realidades, aos interesses e aos valores culturais locais, e estimular a formulação de estratégias intersetoriais para a redução da morbimortalidade por acidentes de trânsito e a melhoria do sistema de informação.

- Capacitar, segundo os pressupostos do programa, os condutores de veículos de grande e pequeno porte, com sede nos municípios selecionados, sensibilizando-os para as questões de violência no trânsito, suas causas, agravos e seqüelas. Tal ação objetiva qualificá-los como agentes multiplicadores das informações junto aos demais associados.

- Desenvolver oficinas de sensibilização com os profissionais de comunicação para utilizarem os espaços da mídia como fonte de disseminação de informações sobre a questão da violência no trânsito e suas estratégias de redução, mobilizando a sociedade e promovendo a saúde.

- Sensibilizar os membros de ONGs e sociedade civil organizada para atuarem como mobilizadores advogando em favor da prevenção de acidentes.

- Capacitar, realizando oficinas nos aglomerados urbanos e capitais selecionadas, os profissionais de saúde, gerentes de serviços de urgência e emergência para: (1) participarem da construção de sistema de notificação compulsória de agravos por causas externas; (2) trabalharem para qualificar a informação; (3) construírem, a partir dessa ficha de notificação elaborada, bancos de dados padronizados nos municípios que possam servir de instrumento de avaliação e acompanhamento das ações de intervenção.

- Disponibilizar para o Conselho Nacional de Trânsito (Contran/Denatran) e demais parceiros os dados consolidados pelos bancos municipais.

- Produzir $100 \%$ dos materiais de apoio às oficinas de trabalho e apoiar a produção dos materiais promocionais contendo as logomarcas do Ministério da Saúde, do Ministério da Justiça e dos municípios conveniados.

- Produzir materiais de apoio à campanha: cartazes, bottons, chaveiros, adesivos, banners, outdoors etc.

- Levantar espaços de veiculação alternativos e oficiais: pontos de encontro de caminhoneiros, pontos de táxis, estações rodoferroviárias, postos de gasolina, lojas de conveniências, oficinas mecânicas, bares, restaurantes, cafés virtuais etc.

- Elaborar material específico sobre a temática, para veiculação na homepage do Ministério da Saúde, estimulando a população a buscar informações também por meio do Disque Saúde e de correio eletrônico.

- Adequar e aprovar os projetos municipais para repasse de recursos aos aglomerados urbanos e capitais selecionadas, levando em conta a proporcionalidade populacional e o índice encontrado. 


\section{Monitoramento e avaliação}

O monitoramento e a avaliação ficarão a cargo da Secretaria de Políticas de Saúde/MS e Denatran/ MJ e compreenderão indicadores de processo e de

\section{REFERÊNCIAS}

1. Ipea/Unicamp.IE.Nesur/IBGE. Caracterização e tendências da rede urbana no Brasil. Campinas: Unicamp.IE; 1999. [Coleção Pesquisas, 3].

2. Ministério da Saúde. Informações de Saúde Mortalidade (1979-98). Disponível em:

http// w.w.w.datasus.gov.br/. resultados, por meio da atuação de equipe multiprofissional, constituída por técnicos dos ministérios e por consultores identificados com a temática que construirão instrumentos e indicadores específicos para essas ações.

3. Opas/OMS. Classificação estatística internacional de doenças e problemas relacionados à saúde - CID 10 . $8^{a}$ ed. São Paulo: Edusp; 2000. 